\title{
Effects of rate of signal rise and decay on reaction time to the onset and offset of acoustic stimuli
}

\author{
JOEL S. WARM, ${ }^{2}$ UNIVERSITY OF CINCINNATI \\ AND EMERSON FOULKE, UNIVERSITY OF LOUISVILLE
}

\begin{abstract}
This study assessed the effects of variations in signal rise-decay time on response latencies to the onset and cessation of a $1,000-\mathrm{Hz}$ tone. Onset and offset reactions were combined factorially with five rates of signal rise-decay $10.5,5$, 25,100 , and $250 \mathrm{msec}$ ) to produce a total of 10 experimental conditions. Offset RTs were significantly longer than onset $R T$ s when the rise-decay time of the tone was 250 msec. Disparities in speed of reaction to tone onset and cessation were negligible at the remaining rates of signal rise-decay.
\end{abstract}

Experimentation concerning the latency of man's reactions to the onset and cessation of acoustic stimuli has yielded equivocal results. Reviews by Teichner (1954) and by Woodworth and Schlosberg (1954) indicate that disparities in speed of reaction to these aspects of auditory stimuli may be negligible. Recently, however, Grier (1966) has presented data showing that reaction time (RT) to the offset of a $1,000-\mathrm{Hz}$ tone tends to be faster than RT to tone onset. Unfortunately, the implications of Grier's experiment are obscured by his use of a continuous white-noise background in which the stimulus tone was embedded. Through the mechanism of masking (see Licklider, 1951, pp. 1005-1009), such a background of stimulation may have elevated detection thresholds for tone onset and thereby provided a bias for securing fastest RTs to the cessation of the tone. Consequently, Grier's study invites replication under conditions in which the auditory signal is presented in the absence of noise. Such a replication was one of the objectives of the present experiment.

To date, studies comparing the latency of reactions to the onset and cessation of acoustic signals have neglected the parameter of stimulus rise-decay time-the rate at which a signal approaches or recedes from maximum amplitude. Yet, data are available that indicate that signal rise-decay time is a critical parameter affecting the speed of reaction to stimulus onset and cessation in another sensory modality, namely, the cutaneous mode. Sticht and Foulke (1966) have reported that RTs to the onsets of electrocutaneous signals were more rapid than RTs to the offsets of such signals when fast rates of rise-decay were used (approximately 0.5 to $150 \mathrm{msec}$ ), and that the opposite effect was noted with more prolonged rise-decay intervals (approximately 150 to $340 \mathrm{msec}$ ). Accordingly, a second aspect of the present investigation was to extend the work of Sticht and Foulke (1966) by exploring the effects of different rates of signal rise-decay on the speed of reaction to the onset and cessation of acoustic stimuli.

\section{Subject}

\section{METHOD}

Ten Ss, five men and five women, between the ages of 20 and 35 years, were employed. None had served previously in RT studies. Ss were paid for their participation in the experiment.

\section{Apparatus and Procedure}

The response signal consisted of the onset or offset of a $1,000-\mathrm{Hz}$ tone presented via earphones at an intensity of $30 \mathrm{~dB}$ SL. The tone was the output of a Hewlett-Packard oscillator, Model 201CR, that was connected to Ss' headphones through a Daven attenuator, Type 7707, and a Grason-Stadler electronic switch. Signal intensity was controlled by both the Daven attenuator and the oscillator attenuator, while the electronic switch permitted variation in the rise and decay time of the tone. The five values of rise-decay time for which the switch could be adjusted were determined by measurements performed on the preserved traces of signals displayed on a Tektronix storage oscilloscope, Model 549, at each of the five switch settings. The measured rise-decay times were: $0.5,5,25,100$, and $250 \mathrm{msec}$ (the rise-decay time in Grier's experiment was $100 \mathrm{msec}$ ). The energy envelopes of the stimulus were compared at signal onset and cessation and found to be identical within a given rise-decay interval. Reactions to stimulus onsets and offsets were obtained at each of the five rise-decay times to produce 10 experimental conditions.

The Ss were seated in an Industrial Acoustic Chamber, Model 400. To secure onset and offset reactions from $S, E$ set his controls and announced, via an intercom between his station outside the acoustic chamber and $S$, that all was ready. When he felt prepared to react, $S$ depressed a Licon
Type 10 momentary switch that operated a Hunter timer (Model 111c) connected to the control circuit of the electronic switch. The timer controlled the foreperiods preceding the appearance of the response signal. When the foreperiod programmed on the timer had elapsed, the timer allowed the response signal to be presented to $S$ by activating the electronic switch. Simultaneously, the timer also activated a Hunter Klockounter. Ss reacted to either tone onset or offset by releasing the momentary switch that, in turn, stopped the Klockounter. Reaction times were read to the nearest millisecond from the dials of the Klockounter. Foreperiods were varied at random from 2 to $4 \mathrm{sec}$ in steps of $0.10 \mathrm{sec}$ for the individual $S$ during each trial of the experimental session. In the onset conditions, the tone commenced at the end of the foreperiod, and $S$ was instructed to respond as soon as he detected its onset. Conversely, the tone was presented at the initiation of the foreperiod during the offset conditions, and $S$ was instructed to respond as soon as he detected the cessation of the tone. In both the onset and offset conditions, $S$ was instructed to respond promptly upon detection of changes in stimulus events and not to wait until full loudness or complete cessation had occurred.

Each $S$ participated in a single experimental session. Sessions were divided into five blocks of 50 trials. In each block, $S$ made five consecutive onset and offset responses to stimuli presented at each of the five rates of signal rise and decay. Hence, over the total session, 25 RTs were obtained per $S$ for each of the 10 factorial combinations of rise-decay time and onset-offset response. The sequence of onset-offset responses was balanced across Ss, while the order of appearance of rise-decay times was varied at random for the individual S. Sessions lasted for $11 / 2 \mathrm{~h}$. Two-minute breaks were provided after each block of trials and whenever $S$ requested a pause. Feedback regarding performance efficiency was not provided.

\section{RESULTS}

Median RTs were obtained for each S under the various experimental conditions. In computing these values, the data from the first block of trials was considered as 


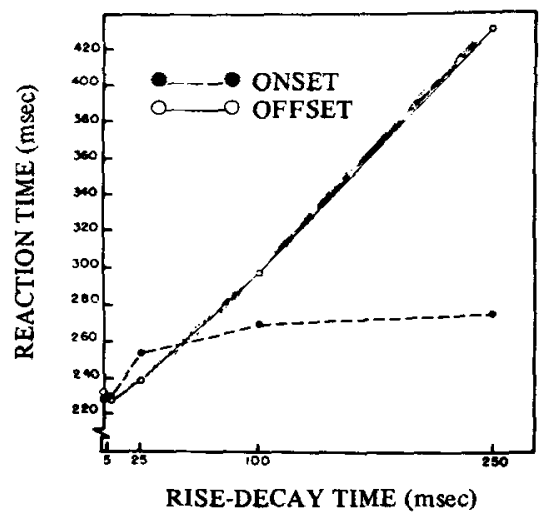

Fig. 1. Reaction times to signal onset and offset at various rates of signal rise and decay.

practice and eliminated. Thus, $S$ 's median RT for each treatment is based upon 20 reactions.

Means of median RTs are plotted in Fig. 1 as a function of rise-decay time, with type of reaction (onset-offset) as the parameter. The figure reveals that RTs to tone onset and cessation were similar at the three fastest rates of signal rise-decay, and that onset reactions became noticeably more rapid than those to tone offset at the two longest rise-decay intervals. The figure also shows that increments in rise-decay time were associated with more pronounced reductions in the speed of offset RTs relative to onset RTs. An increase of only $46 \mathrm{msec}$ can be observed in the latency of onset reactions as the rise-decay intervals increased from 0.5 to 250 msec. By contrast, an increase of 204 msec can be noted in offset RTs over the same rise-decay range.

An analysis of variance of the data revealed statistically significant effects for rise-decay time $(F=112.38, d f=4 / 36$, $p<.01)$ and type of response $(F=8.11$, $\mathrm{df}=1 / 9, \quad \mathrm{p}<.05)$ and $\mathrm{a}$ significant interaction between these variables $(F=35.77$, df $=4 / 36, p<.01)$. In view of this interaction, comparisons were made between onset and offset response latencies at each rise-decay interval. Onset RTs were significantly more rapid than offset RTs when the rise-decay time of the tone was $250 \mathrm{msec}(\mathrm{F}=34.14$, df $=1 / 9, \mathrm{p}<.01)$. All other postmortem comparisons lacked significance.

\section{DISCUSSION}

In a prior study, Grier (1966) reported that RTs to the onset of a tone embedded in white noise were slower than were reactions to the cessation of the tone. Contrary to Grier's findings, the present data indicate that when a tone is presented in the absence of a noise background, onset
RTs are either equal to or more rapid than offset RTs, depending upon the rise and decay time of the signal. Such a result implies support for the contention that Grier's use of a noise background may have partially masked the onset of the tone and thus provided a bias toward shorter response latencies to tone offset.

The present experiment was designed, in part, to investigate the sensory generality of Sticht and Foulke's (1966) finding regarding the interaction between the rise-decay time of electrocutaneous signals and the latency of reactions to stimulus onset and cessation. Although the rise-decay times of the auditory stimuli in the present study were similar to those employed by Sticht and Foulke, the interaction between rise-decay time and the speed of onset and offset reactions found here differed clearly from that of their report. Electrical current applied to the skin represents a nonadequate stimulus that may bypass receptor organs and excite cutaneous nerves directly (Hawkes, 1961; Sticht, 1968). By contrast, the present data are based upon adequate acoustic stimulation. Disparities between the present results and those of Sticht and Foulke (1966) may reflect differences in neural mechanisms due to the types of stimulation employed in the two experiments.

The relatively small increase in onset RTs noted in the present data with increments in the rise-decay time of the tone may be related to the threshold of audibility. In reacting to tone onset, $S$ was responding to the appearance of a signal in a background of relative quiet. The ability of the ear to detect signals at extremely low energy levels under such conditions is well known (Davis, 1959; Geldard, 1953; Harris, 1950). Therefore, within the range of rise times used here, delays in the temporal interval necessary to reach the energy level required for threshold may have been insufficient to produce gross variations in the speed of onset reactions.

The more pronounced increment in the latency of offset reactions with delays in signal rise-decay time may perhaps be due to the fact that decays in the physical intensity of an acoustic signal are not accompanied by an immediate corresponding decline in apparent loudness. According to Békésy (1960), changes in the loudness of a tone at offset lag behind the physical decay process. Moreover, the curves presented by Békésy indicate that disparities between the rate of decline in perceived intensity and the rate of decline in physical intensity are amplified by extensions of the physical decay time of the signal. It is conceivable that such lags in the loudness of the stimulus tone with increments in physical decay time could have resulted in the comparatively large increase in offset response latencies noted here. In sum, it is suggested that, with extensions of physical rise-decay time, progressively greater inertia in the response of the auditory system to changes in stimulus events at signal offset relative to onset may explain the results of this investigation.

\section{REFERENCES}

BÉKÉSY, G. V. Experiments in hearing. New York: McGraw-Hill, 1960.

DAVIS, H. Excitation of auditory receptors. In J. Field, H. W. Magoun, and V. E. Hall (Eds.), Handbook of physiology. Section 1: Neurophysiology. Washington, D.C.: American Physiological Society, 1959. Pp. 565-584.

GELDARD, F. A. The human senses. New York: Wiley, 1953.

GRIER, J. B. Reaction time to tone off. Psychonomic Science, 1966, 5, 385-386.

HARRIS, J. D. Some relations between audition and vision. Springfield, Ill.: Charles $\mathrm{C}$ Thomas, 1950.

HAWKES, G. R. Cutaneous discrimination of electrical intensity. American Journal of Psychology, 1961, 74, 45.53.

LICKLIDER, J. C. R. Basic correlates of the auditory stimulus. In S. S. Stevens (Ed.), Handbook of experimental psychology. New York: Wiley, 1951. Pp. 985-1039.

STICHT, T. C. Threshold and response-latency as a function of the rise-time of a.c. electrical stimuli. American Journal of Psychology, $1968,81,384-390$.

STICHT, T. C., \& FOULKE, E. Reaction time to the onset and offset of electrocutaneous stimuli as a function of rise and decay time. Perception \& Psychophysics, 1966, 1, 361-365.

TEICHNER, W. H. Recent studies of simple reaction time. Psychological Bulletin, 1954, $51,128-149$.

WOODWORTH, R. S., \& SCHLOSBERG, H. Experimental psychology. (Rev. ed.) New York: Holt, 1954.

\section{NOTES}

1. Supported in part by the U.S. Army Medical Research and Development Command Department of the Army, under Research Contract No. DADA17-68-C-8059, "Stimulus Factors in Human Timing Behavior." The authors are indebted to Drs. Kenneth G. Donnelly, Michel Loeb, Donald A. Schumsky, and Marvin Schwartz, for their helpful comments and to Mr. John Shaugnessy for technical assistance.

2. Address: Department of Psychology, University of Cincinnati, Cincinnati, Ohio 45221.

3. The data presented here constitute a replication of an earlier study conducted in this laboratory. During the initial experiment, delays were noted in the response of the electronic switch, which controlled signal rise-decsy time, to commands from the timer controlling the foreperiods. These delays were measured under all experimental conditions and appropriate corrections were made in scoring the data. In the present experiment, delays in the response of the electronic switch to commands from the timer were eliminated. The outcome of both experiments was identical in spite of this difference in the operation of the equipment.

(Accepted for publication June 5, 1969.) 